\title{
Acute pancreatitis complicated with deep vein thrombosis and pulmonary embolism: a case report
}

\author{
H. M. M. T. B. Herath ${ }^{*}$ and Aruna Kulatunga
}

\begin{abstract}
Background: Acute pancreatitis is an acute inflammatory process of the pancreas that can trigger a systemic inflammatory response. Pulmonary embolism refers to obstruction of the pulmonary artery or one of its branches by material (usually a thrombus) that originated elsewhere in the body. Extensive lower limb deep vein thrombosis with pulmonary embolism is a rare complication of acute pancreatitis that has been described in a few case reports. Deep vein thrombosis and hypercoagulable states in pancreatitis are thought to be due to release of pancreatic proteolytic enzymes from a cyst that is connected to the pancreatic duct and penetrates into a vessel. Proteolytic damage or inflammation of the vessels may also play a significant part. Acute pancreatitis also causes a systemic inflammatory response that has effects on an endothelium-dependent relaxing response for acetylcholine.

Case presentation: A 38-year-old Sri Lankan man presented with acute pancreatitis and later he developed progressive abdominal distention with bilateral ankle edema. A contrast-enhanced computed tomographic scan showed two pancreatic pseudocysts and deep vein thrombosis in both lower limbs, as well as a pulmonary embolism involving the right lower lobe pulmonary artery and the left segmental pulmonary arteries. One of the pseudocysts in the head of the pancreas was compressing the inferior vena cava without direct communication. The patient's thrombophilia screen result was negative. He was started on subcutaneous enoxaparin $1 \mathrm{mg} / \mathrm{kg}$ twice daily and warfarin to achieve a target international normalized ratio of 2-3.

Conclusions: Deep vein thrombosis with pulmonary embolism is a rare but life-threatening complication of acute pancreatitis. Once diagnosed, early treatment with intravenous heparin or thrombolysis is effective. Patients with severe acute pancreatitis may be at risk of deep vein thrombosis due to immobilization and other mechanisms, but anticoagulation as prophylaxis is often not used. However, it may be considered on a case-by-case basis in patients with pancreatitis who are acutely ill and immobilized, need intensive care unit admission, and have multiple risk factors for deep vein thromboembolism. Further studies must be undertaken to determine guidelines for deep vein thromboembolism prophylaxis in these patients.
\end{abstract}

Keywords: Acute pancreatitis, Deep vein thrombosis, Pulmonary embolism, Case report

\section{Background}

Acute pancreatitis is an acute inflammatory process of the pancreas characterized by local tissue injury that can trigger a systemic inflammatory response and is mostly associated with alcoholism or gallstones. The disease is of varying severity. Hemorrhage resulting from an arterial erosion or pseudoaneurysm formation, ischemic complications, and a hypercoagulable state causing venous

\footnotetext{
* Correspondence: tharukaherath11@gmail.com
}

National Hospital Of Sri Lanka, Colombo, Sri Lanka thrombosis (specifically splanchnic thrombosis) are some of the vascular complications of acute pancreatitis [1].

Pulmonary embolism refers to obstruction of the pulmonary artery or one of its branches by material (usually a thrombus) that originated elsewhere in the body. It arises mostly from the deep venous system of the lower extremities [2]. Extensive lower limb deep vein thrombosis (DVT) with pulmonary embolism is a rare complication of acute pancreatitis. In this report, we describe a patient who presented with acute pancreatitis due to chronic alcohol ingestion complicated by bilateral 
common iliac and left external iliac thrombosis and pulmonary embolism. A pseudocyst at the head of the pancreas was found to be compressing the inferior vena cava. The results of the patient's genetic and other thrombophilia screens were negative.

\section{Case presentation}

One year before his current presentation, a 38-year-old Sri Lankan man who had previously been well went to the local hospital with intermittent severe epigastric pain radiating to his back, in addition to vomiting. At this initial presentation, acute pancreatitis with high amylase levels was diagnosed. He had been consuming around 12 units of alcohol per week for a 12-year period. He did not have diabetes, hypertension, cholelithiasis, thromboembolic disease, or any other medical disease. He had no family history of significant medical illness. Following this presentation, he had intermittent episodes of epigastric pain, which subsided spontaneously without any medical treatment. At his current presentation, he had a 1-month history of steatorrhea and abdominal pain. His abdominal pain was intermittent and was associated with vomiting. He did not have fever. His initial serum amylase level was high. He was not immobilized. On the third day of admission, he developed progressive abdominal distention with bilateral ankle edema and normal urine output. He was not breathless.

His physical examination revealed that his body mass index was $21.6 \mathrm{~kg} / \mathrm{m}^{2}$. He was afebrile and pale and had ankle edema. He had a pulse rate of 80 beats per minute, and his blood pressure was $130 / 80 \mathrm{mmHg}$. His jugular venous pressure was elevated $(8 \mathrm{~cm})$. He was not tachypneic, and both lower zones of his lungs were dull to percussion. His breath sounds were reduced without any added sounds. His abdomen was tensely distended and tender, with gross ascites.

The patient's amylase level was rising. On day 1 of admission (1 month after symptoms started), his amylase level was $1331 \mathrm{U} / \mathrm{L}$; on day 2, it was $1780 \mathrm{U} / \mathrm{L}$; and on day 3, it was $3570 \mathrm{U} / \mathrm{L}$. His amylase level remained elevated for 3 weeks. His white blood cell count (WBC) was $11.04 \times$ $10^{3} / \mu \mathrm{L}$ with $70 \%$ neutrophils. His hemoglobin level was $6.7 \mathrm{~g} / \mathrm{dl}$, with a hematocrit of $24.9 \%$ on admission (normal $37-54 \%)$. On day 2 of admission, his hematocrit was $25.6 \%$. His platelet count was $243 \times 10^{9} / \mathrm{L}$. Hypochromic microcytic red blood cells (RBC) with a few pencil-shaped cells and macrocytes as well as hypersegmented neutrophils were visualized by mircroscopy. The patient's reticulocyte index was normal, and the result of his Coombs test was negative. His serum ferritin level was $37.0 \mu \mathrm{g} / \mathrm{L}$ (normal $25-240 \mu \mathrm{g} / \mathrm{L}$ ), his serum iron level was $13.4 \mu \mathrm{g} / \mathrm{dl}$ (normal $37-148 \mu \mathrm{g} / \mathrm{dl}$ ), his total iron-binding capacity was $296 \mu \mathrm{g} /$ $\mathrm{dl}$ (normal $274-385 \mu \mathrm{g} / \mathrm{dl}$ ), and his iron saturation was $4.5 \%$ (normal $15-50 \%$ ).
The patient's liver function tests were within normal range, except for a marginally low albumin level (aspartate aminotransferase $14 \mathrm{U} / \mathrm{L}$, alanine transaminase $10 \mathrm{U} / \mathrm{L}$, alkaline phosphatase $125 \mathrm{U} / \mathrm{L}$, total bilirubin $18 \mu \mathrm{mol} / \mathrm{L}$, total protein $48 \mathrm{~g} / \mathrm{L}$, albumin $32 \mathrm{~g} / \mathrm{L}$, globulin $16 \mathrm{~g} / \mathrm{L}$, international normalized ratio [INR] 1.23). His erythrocyte sedimentation rate was $56 \mathrm{~mm} / \mathrm{h}$ in the first hour, and his C-reactive protein (CRP) levels were $35 \mathrm{mg} / \mathrm{L}$ on admission and $24 \mathrm{mg} / \mathrm{L}$ (normal $0-5 \mathrm{mg} / \mathrm{L}$ ) after 48 hours. His serum ionized calcium on day 2 of admission was $0.91 \mathrm{mmol} / \mathrm{L}$ (normal 1.09-1.3 $\mathrm{mmol} / \mathrm{L}$ ), and it was $1.14 \mathrm{mmol} / \mathrm{L}$ with replacement of calcium on day 5 . His serum creatinine concentration was within normal range throughout $(75,88$, and $78 \mu \mathrm{mol} / \mathrm{L}$; normal $60-120$ $\mu \mathrm{mol} / \mathrm{L}$ : on days 1,2 and 5 respectively), and his blood urea nitrogen level was normal $(2.6 \mathrm{mmol} / \mathrm{L}$, normal 2.9 $8.2 \mathrm{mmol} / \mathrm{L}$ ). His serum sodium level was $133 \mathrm{mmol} / \mathrm{L}$, and his serum potassium concentration was $3.3 \mathrm{mmol} / \mathrm{L}$. His random blood sugar level on admission was $126 \mathrm{mg} / \mathrm{dl}$. Arterial blood gas analysis showed a $\mathrm{pH}$ of 7.5 with partial pressure of carbon dioxide of $31.4 \mathrm{mmHg}$, bicarbonate of $30.0 \mathrm{mmol} / \mathrm{L}$, base excess of +8.0 , lactate of $1.0 \mathrm{mmol} / \mathrm{L}$ (normal 1.0-2.5 mmol/L), oxygen saturation of $95.8 \%$, and partial pressure of oxygen of $73.4 \mathrm{mmHg}$. His fasting blood sugar level was $5.6 \mathrm{mmol} / \mathrm{L}$ (normal $<5.6 \mathrm{mmol} / \mathrm{L}$ ). His lipid profile was normal, with a normal triglyceride level of $120 \mathrm{mg} / \mathrm{dl}$. His thyroid-stimulating hormone level was $0.97 \mathrm{mIU} / \mathrm{L}$ (normal $0.55-4.78 \mathrm{mIU} / \mathrm{L}$ ), and his free thyroxine was 1.54 (normal 0.89-1.76).

An ultrasound scan of the abdomen showed gross ascites with a normal liver and kidneys. Contrast-enhanced computed tomography (CECT) of the abdomen revealed two pancreatic pseudocysts, measuring $4.5 \mathrm{~cm} \times 3.5 \mathrm{~cm}$ and $4.2 \mathrm{~cm} \times 5 \mathrm{~cm}$, respectively, in relation to the pancreatic head (Fig. 1). The pancreatic duct and the rest of the pancreas were normal, without evidence of necrosis or changes of chronic pancreatitis. Gross ascites was visualized on both an ultrasound scan of the abdomen and a CECT scan. The patient's bowel appeared normal. His peritoneal fluid was an exudate with $4.3 \mathrm{~g} / \mathrm{dl}$ protein and a serum-to-ascites albumin gradient of $-1.1 \mathrm{~g} / \mathrm{dl}(<1.1 \mathrm{~g} / \mathrm{dl})$, a lactic acid dehydrogenase level of $527 \mathrm{U} / \mathrm{L}, \mathrm{WBC}$ of 73 cells $/ \mathrm{mm}^{3}$ with $90 \%$ lymphocytes, and RBC of $1.6 \times 10^{9} /$ $\mathrm{mm}^{3}$. His ascitic fluid amylase level was high at $3618 \mathrm{IU} / \mathrm{L}$. No malignant cells were seen, and the patient's Gram stain and acid-fast bacilli smear results were negative, with the culture remaining sterile. His adenosine deaminase level was normal (12 IU/L).

One of the pseudocysts in the head of the pancreas was compressing the inferior vena cava (IVC), as shown in the CECT scans in Figs. 2, 3 and 4. There were filling defects in the left common and internal iliac veins and both proximal external iliac veins, suggesting DVT (Figs. 5 and 6). The patient's IVC was patent. Multiple 


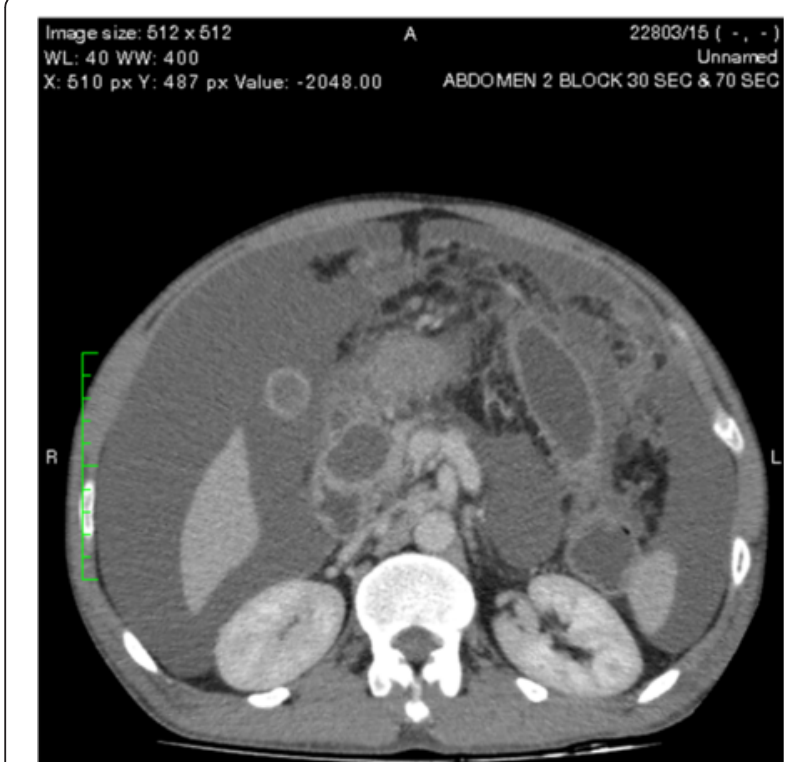

Fig. 1 Two pancreatic pseudocysts, measuring $4.5 \mathrm{~cm} \times 3.5 \mathrm{~cm}$ and $4.2 \mathrm{~cm} \times 5 \mathrm{~cm}$, respectively, in relation to the pancreatic head

filling defects were seen in the right lower lobe pulmonary artery and in segmental branches of the left pulmonary artery, compatible with pulmonary embolism (Figs. 7 and 8). The patient's liver, gallbladder, spleen, kidneys, and adrenal glands were normal. He had bilateral atelectasis of the lung bases with minimal pleural effusions.

Venous Doppler sonography of the patient's lower limbs did not reveal DVT in the femoral and popliteal veins. The patient's D-dimer level was $1.43 \mathrm{mg} / \mathrm{L}$. His left ventricular ejection fraction was $55 \%$, with diastolic

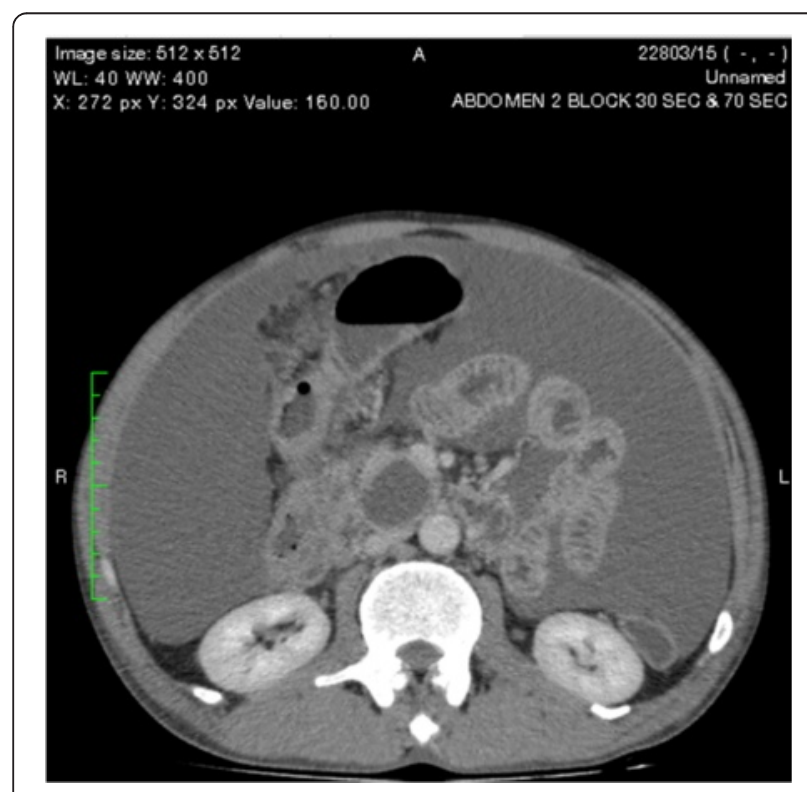

Fig. 2 One of the pseudocysts in the head of the pancreas compressing the inferior vena cava

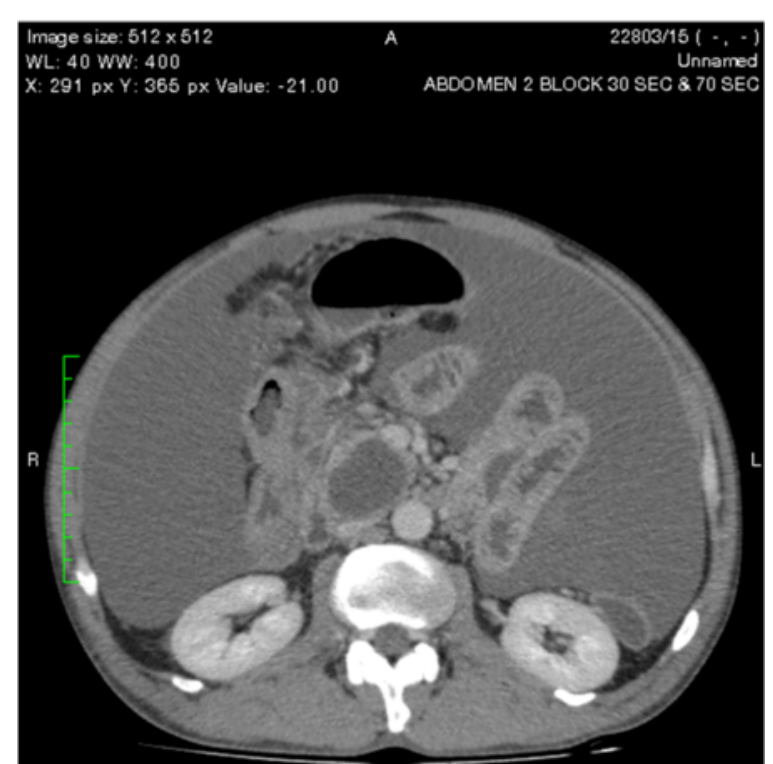

Fig. 3 The pseudocysts compressing the inferior vena cava without any direct communication

dysfunction visualized on a two-dimensional echocardiogram. His main pulmonary artery was normal, with a pressure gradient of $23 \mathrm{mmHg}$, and his right ventricular function was good.

His antinuclear antibody and anticardiolipin antibody test results were negative. He had no nocturnal hematuria, and the findings in three consecutive early morning samples were negative for hemosiderin. The results of genetic testing for prothrombin gene mutation, factor $\mathrm{V}$ Leiden, and MTHFR gene mutation were negative. The results of

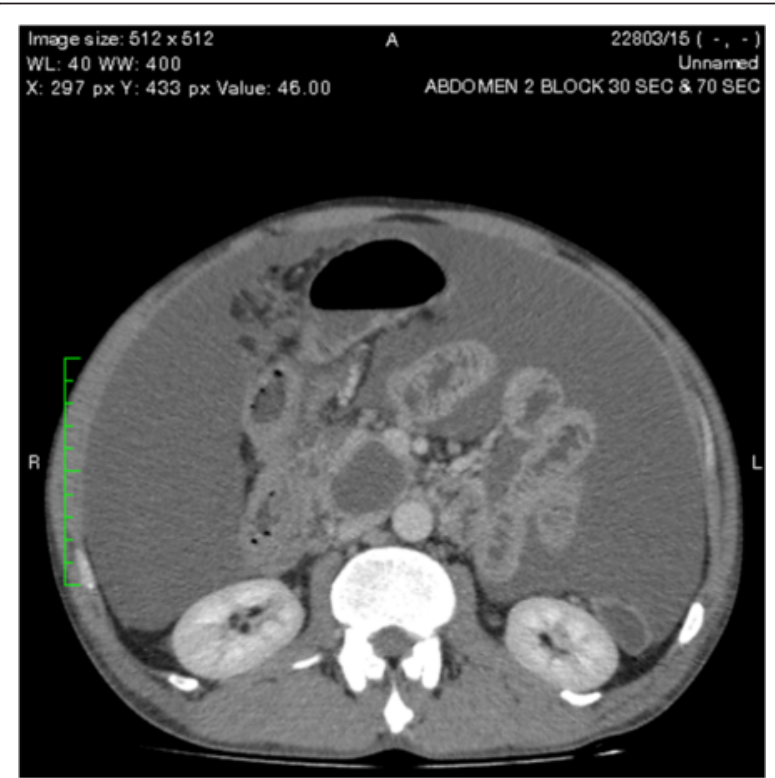

Fig. 4 The level that the inferior vena cava maximally got compressed 


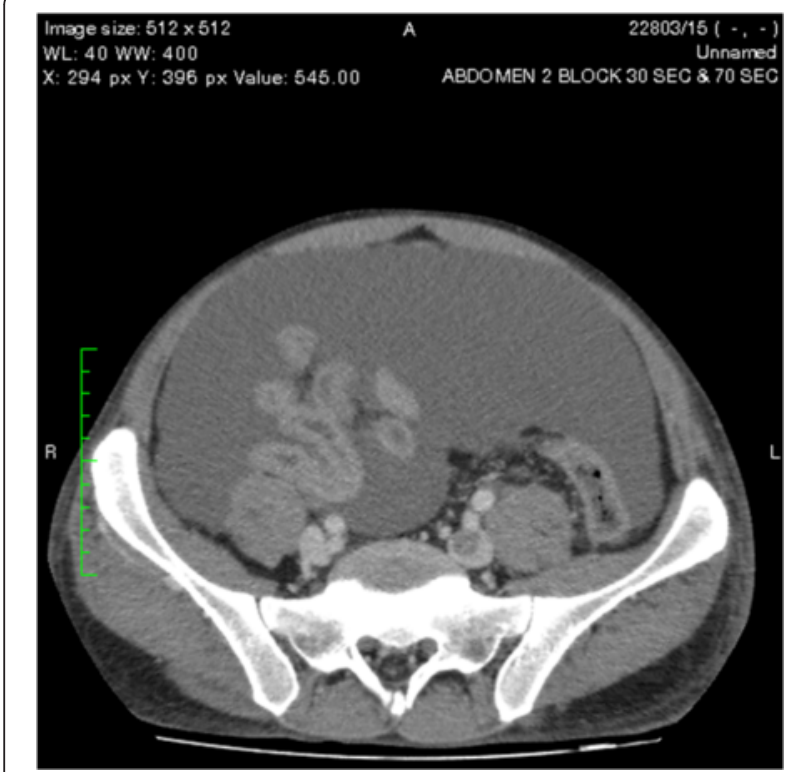

Fig. 5 Filling defects in the left common iliac vein

the patient's Ham test and the thrombophilia screen for antithrombin III as well as protein $\mathrm{C}$ and protein $\mathrm{S}$ deficiency were negative. His test result for dengue antibodies was negative. The results of his monospot test for Epstein-Barr virus, hepatitis B surface antigen, and hepatitis $\mathrm{C}$ antibodies were negative. His test result for HIV was also negative, and his VDRL was nonreactive. His upper gastrointestinal endoscopy was normal initially. His carcinoembryonic antigen level was $0.9 \mu \mathrm{g} / \mathrm{L}$ (normal $<5 \mu \mathrm{g} / \mathrm{L}$ ).

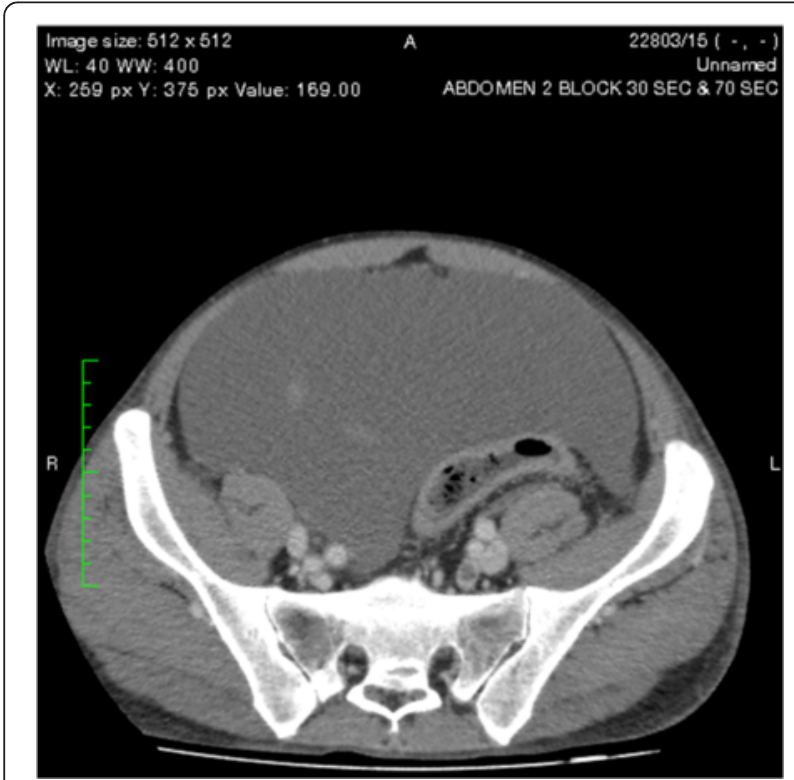

Fig. 6 Filling defects in the left internal iliac vein

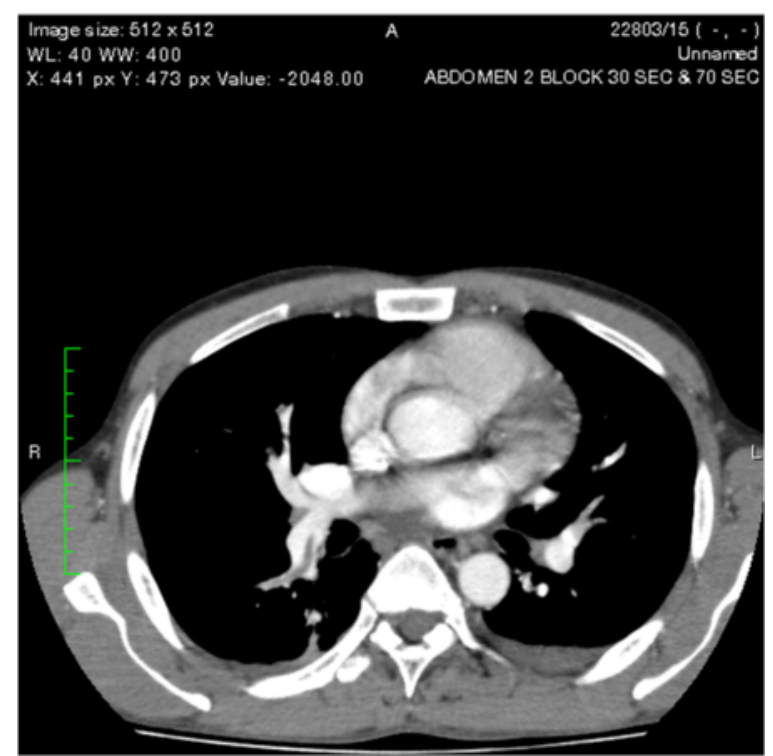

Fig. 7 Multiple filling defects were seen in the right lower lobe pulmonary artery

After the diagnosis of DVT and pulmonary embolism was made, the patient was started on subcutaneous enoxaparin $1 \mathrm{mg} / \mathrm{kg}$ twice daily and warfarin to achieve a target INR of 2-3. Initially, he was kept nil orally; later, gradual enteral feeding was introduced. Calcium was replaced orally. Later, he developed bleeding into the peritoneal cavity with a high INR, and $6 \mathrm{U}$ of blood were transfused. He was managed in the intensive care unit (ICU) during this period, and total parenteral nutrition was given. His bleeding settled spontaneously with INR

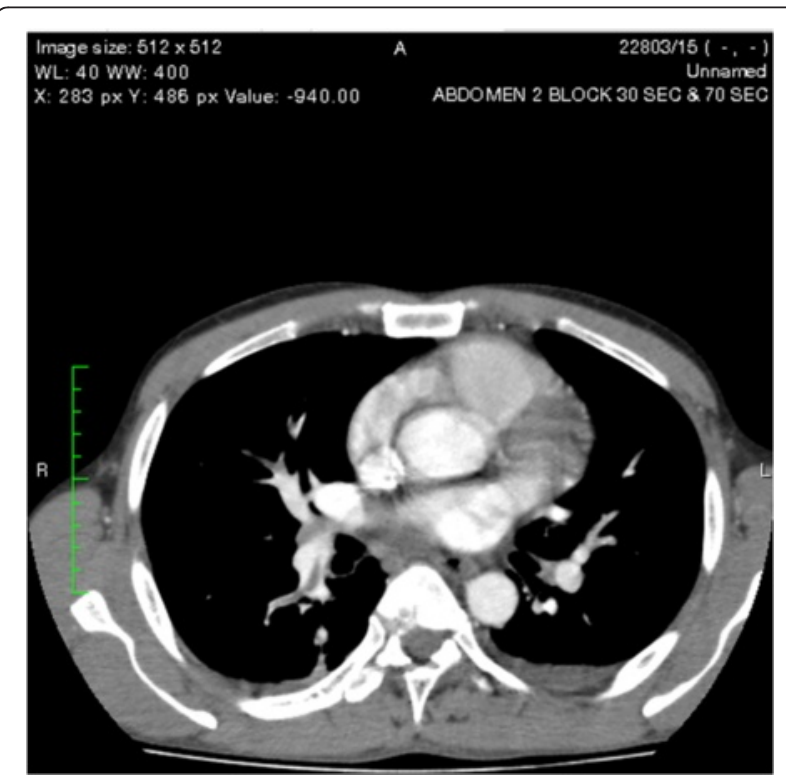

Fig. 8 Multiple filling defects were seen in the right lower lobe pulmonary artery 
correction. His ascitic fluid and large pseudocyst were drained using a pigtail catheter. The pigtail catheter was kept in place until the drainage stopped, and then it was removed. After 10 days in the ICU, the patient recovered and was discharged on oral warfarin to achieve a target INR of $2-3$. He was planned to be treated with anticoagulation for 6 months because he did not have any other acquired or congenital risk factors for thromboembolism.

\section{Discussion}

Acute pancreatitis is inflammation of the pancreas that presents as abdominal pain with elevated levels of pancreatic enzymes in the blood. Serum amylase is the most frequent test used to diagnose acute pancreatitis, and computed tomography is the most important imaging tool for the diagnosis and assessment of severity of pancreatitis.

According to the revised Atlanta classification system, our patient had interstitial edematous acute pancreatitis, a disease in which there is acute inflammation of the pancreatic parenchyma and peripancreatic tissues but without tissue necrosis [3]. The patient had no hemoconcentration, and his CRP was below $150 \mathrm{mg} / \mathrm{dl}$ at 48 hours [4]. His Balthazar score was grade 4 [5]. His Ranson criteria scores were 0 on admission and 2 at 2 hours, giving a 0-3 \% mortality [6]. His Acute Physiology and Chronic Health Evaluation II score was 8.0 points with $6 \%$ estimated nonoperative mortality [4]. His Bedside Index for Severity in Acute Pancreatitis score was 1, with a mortality rate less than $2 \%$. His gross ascites was disproportionate to the severity of his pancreatitis, but this could be explained by the presence of a pancreatic fistula producing pancreatic ascites (Figs. 9 and 10).

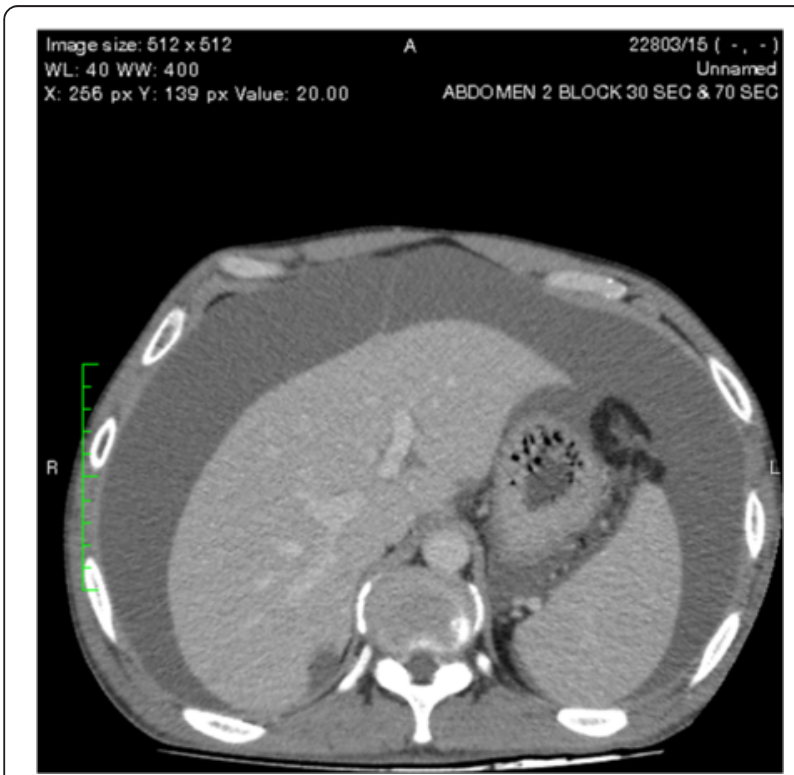

Fig. 9 Gross ascites at the level of the liver and spleen

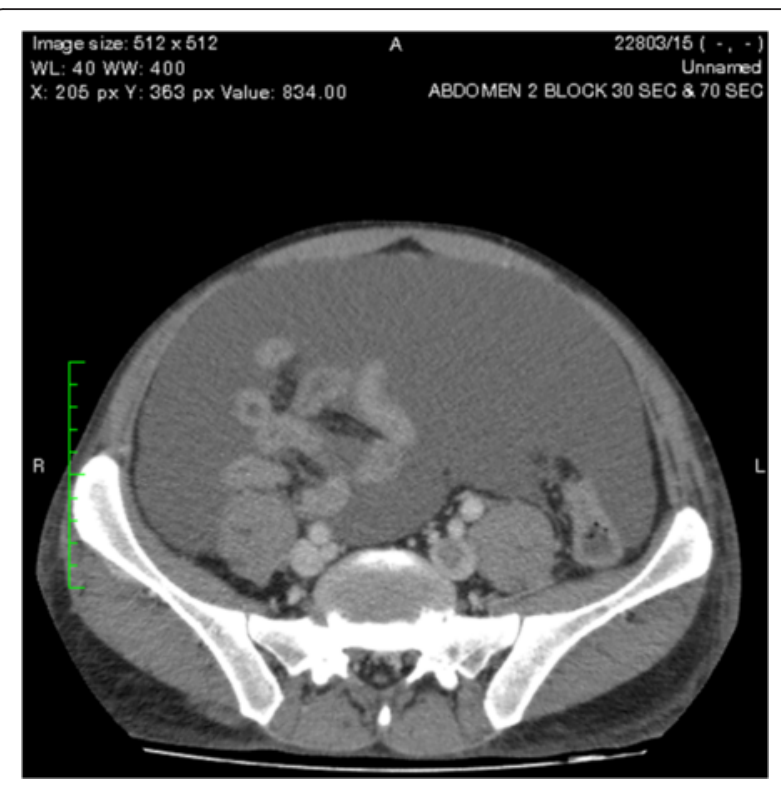

Fig. 10 Gross ascites with freely floating bowel loops

Vascular complications of pancreatitis are a major cause of morbidity and mortality. Venous complications are predominantly related to splanchnic vein thrombosis due to local inflammation [1]. Pulmonary embolism is a rare complication of pancreatitis that has been described in few case reports [7]. Renal vein and IVC thrombosis associated with acute pancreatitis has been reported [8]. DVT and hypercoagulable states in pancreatitis are thought to be due to release of pancreatic proteolytic enzymes from a cyst that is connected to the pancreatic duct and penetrates into a vessel. The pancreatic juice triggers the formation of a thrombus secondary to vasculitis. Proteolytic damage or inflammation of the vessels may also play a significant part, and pancreatic elastase has been shown to play a major role in the development of pulmonary vascular injury after acute pancreatitis [9]. It is also thought that hypercoagulability in pancreatitis is due to a combination of hepatic dysfunction and hypertrypsinemia (resulting in raised fibrinogen and factor VIII concentrations) and cachexia. Acute pancreatitis provokes deleterious effects in the endotheliumdependent relaxing response for acetylcholine in mesenteric rings that are strongly associated with high plasma nitrite/ nitrate levels as a consequence of intense inflammatory responses. Furthermore, the subsensitivity of the contractile response to phenylephrine in both mesenteric and pulmonary rings might be due to the complications of this pathological condition in the early stage of pancreatitis [10]. In DVT, immobility may also contribute. In our patient, one of the pancreatic pseudocysts was compressing the IVC, as shown on CECT of the abdomen, although direct communication was not seen. 
A thrombophilic state leading to venous thrombosis can be inherited or acquired. Our patient did not have any acquired causes and had negative test results for other prothrombotic conditions. Therefore, we conclude that the patient's DVT and pulmonary embolism were secondary to acute pancreatitis.

Early recognition, as well as investigation and diagnosis, of pulmonary embolisms is important, because early treatment with intravenous heparin and radiological interventional procedures such as vascular filters can reduce mortality. The American College of Chest Physicians 2008 guidelines [11] recommend venous thromboembolism prophylaxis with low-molecular-weight heparin in patients undergoing major general surgery, major gynecologic surgery, major open urologic procedures, and elective hip or knee arthroplasty, as well as in all major trauma and spinal cord injury patients and patients admitted to the hospital with an acute medical illness. On admission to the ICU, all patients should be assessed for their risk of venous thromboembolism, and most should receive thromboprophylaxis.

\section{Conclusions}

Deep vein thrombosis with a pulmonary embolism is a rare but life-threatening complication of acute pancreatitis. If clinically suspected, necessary investigations should be arranged. Once diagnosed, early treatment with intravenous heparin or thrombolysis is effective, and other causes of thrombophilia should be looked for. Patients with severe acute pancreatitis may be at risk of DVT due to immobilization and the mechanisms mentioned above in the Discussion section. However, anticoagulation as prophylaxis is often not used, because these patients may need intervention (pigtail catheter drainage or surgery) and may be at an increased risk of bleeding [12]. It may be considered on a case-by-case basis in patients with pancreatitis who are acutely ill, immobilized, need ICU admission, and have multiple risk factors for deep vein thromboembolism. Further studies must be undertaken to determine guidelines for deep vein thromboembolism prophylaxis in these patients.

\section{Acknowledgements}

This case report was supported by ward doctors with regard to the acquisition, analysis, and interpretation of data. We are thankful to the patient's relatives for support given in providing data.

\section{Authors' contributions}

HMMTBH collected data, followed the patient, did the literature review, and drafted the manuscript. AK drafted and corrected the manuscript. Both authors read and approved the final manuscript.

Competing interests

The authors declare that they have no competing interests.

\section{Consent for publication}

Written informed consent was obtained from the patient for publication of this case report and any accompanying images. A copy of the written consent is available for review by the Editor-in-Chief of this journal.

Received: 6 March 2016 Accepted: 2 June 2016

Published online: 23 June 2016

\section{References}

1. Mendelson RM, Anderson J, Marshall M, Ramsay D. Vascular complications of pancreatitis. ANZ J Surg. 2005;75:1073-9.

2. Kistner RL, Ball JJ, Nordyke RA, Freeman GC. Incidence of pulmonary embolism in the course of thrombophlebitis of the lower extremities. Am J Surg. 1972;124:169-76.

3. Banks PA, Bollen TL, Dervenis C, Gooszen HG, Johnson CD, Sarr MG, et al. Classification of acute pancreatitis - 2012: revision of the Atlanta classification and definitions by international consensus. Gut. 2013;62:102-11.

4. Larvin M. Assessment of clinical severity and prognosis. In: Beger HG, Warshaw AL, Büchler MW, et al., editors. The pancreas, vol. 1. Oxford: Blackwell; 1998. p. 489.

5. Balthazar EJ, Robinson DL, Megibow AJ, Ranson JH. Acute pancreatitis: value of CT in establishing prognosis. Radiology. 1990;174(2):331-6.

6. Banks PA, Freeman ML, Practice Parameters Committee of the American College of Gastroenterology. Practice guidelines in acute pancreatitis. Am J Gastroenterol. 2006;101(10):2379-400.

7. Uchiyama T, Yamamoto T, Mizuta E, Suzuki T. Pancreatic ascites-a collected review of 37 cases in Japan. Hepatogastroenterology. 1989;36(4):244-8.

8. Ma SK, Kim SW, Kim NH, Choi KC. Renal vein and inferior vena cava thrombosis associated with acute pancreatitis. Nephron. 2002;92:475-7.

9. Lungarella G, Gardi C, de Santi MM, Luzi P. Pulmonary vascular injury in pancreatitis: evidence for a major role played by pancreatic elastase. Exp Mol Pathol. 1985:42:44-59.

10. Camargo EA, Delbin MA, Ferreira T, Landucci EC, Antunes E, Zanesco A. Influence of acute pancreatitis on the in vitro responsiveness of rat mesenteric and pulmonary arteries. BMC Gastroenterol. 2008;8:19.

11. Geerts WH, Bergqvist D, Pineo GF, Heit JA, Samama CM, Lassen MR, et al. Prevention of venous thromboembolism: American College of Chest Physicians Evidence-Based Clinical Practice Guidelines (8th Edition). Chest. 2008;133(6 Suppl):381S-453.

12. Rana SS, Sharma V, Bhasin DK, Sharma R, Gupta R, Chhabra P, et al. Gastrointestinal bleeding in acute pancreatitis: etiology, clinical features, risk factors and outcome. Trop Gastroenterol. 2015;36(1):31-5.

Submit your next manuscript to BioMed Central and we will help you at every step:

- We accept pre-submission inquiries

- Our selector tool helps you to find the most relevant journal

- We provide round the clock customer support

- Convenient online submission

- Thorough peer review

- Inclusion in PubMed and all major indexing services

- Maximum visibility for your research 